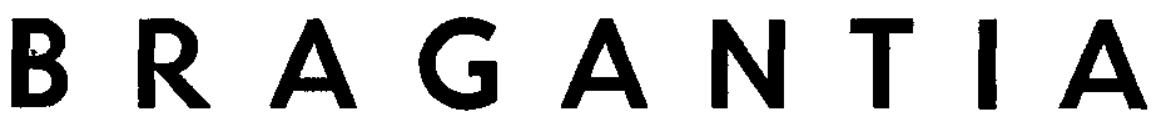

Revista Científica do Instituto Agronômico do Estado de São Paulo

Vol. 34

Campinas, agosto de 1975

N. ${ }^{\circ} 14$

\title{
CULTIVO DE CAFE EM LATOSSOLO VERMELHO-AMARELO DA REGIÃO DE BATATAIS, SP $(1,2)$
}

Walter lazzarini ( 3 ), Ferdinando Roberto Pupo de Morais ( 4 ), Genísio da Silva Cervellini ( $\left.{ }^{4}\right)$, Sérgio Vasco de Toledo e Joaquim Ignácio DE Figueirado ( $\left.{ }^{4}\right)$, Seção de Café, ANTônio Junquarra Reis, Estaçāo Experimental de Ribeiräo Preto, Armando Conagin, Divisäo de Plantas Alimenticias Básicas, Instituto Agronómico, e CoAracy Morals Franco, Instituto Brasileiro do Café

\section{SLNOPSE}

Săo relatados os resultados de um experimento com cafeeiros em latossolo vermelho-amarelo (terra de campo cerrado) de baixíssima fertilidade natural e considerado, na ocasião, como impróprio para as atividades agricolas normais.

Foram comparados sete tratamentos de adubação, sendo três à base de esterco e quatro à base de fertilizantes exclusivamente químicos, além de um controle náo adubado.

Foram efetuadas observaçōes sobre o efeito das vários tratamentos sobre o crescimento e o estado nutricional dos cafeelros em relaçáo com a ocorrência de sintomas de carência de vários elementos.

A análise das produçôes obtidas durante o periodo $1960 / 69$ revelou que o emprego de adubaçōes exclusivamente químicas em presença de calćario e micronutrientes fol superior ao emprego de esterco isoladamente e equivalente a este complemento pela adubaçăo química e calagem.

O emprego dos micronutrientes e do calcário teve efeito significativo no aumento da produçáo.

O emprego do calcário fol altamente eficaz na correçăo da carêncla de magnésio e no aumento da produçăo.

Os resultados obtidos indicam que é viável a exploraçăo económica do cafeeiro no latossolo vermelho-amarelo de baixa fertilidade, através do uso exclusivo da adubaçăo química.

(1) Dados parclais apresentados na 1." Reunižo da FAO sobre Produção e Proteçฐ̃ do Café, Rio de Janeiro, 1965, e no XI Cong. bras, de Ciência do Solo, Brasília-DF, 1967. Rece. bldo para publicą̧ấo $\mathrm{em} 13$ de majo de 1975 .

$\left.{ }^{2}\right)$ Trabalho parcialmente subvencionado com recursos do Acordo IBC-DAC-SA Instituto Agron6mico.

$\left({ }^{3}\right)$ Coordenador do projeto ate junho de 1964.

( ${ }^{4}$ Com bolsas de suplementagđo do C.N.Pq. 


\section{1 - INTRODUÇÃO}

Durante muito tempo o cafeeiro foi considerado pelos técnicos como sendo uma planta exigente em solos ricos de matéria orgânica, acreditando-se que a falta desta era o principal obstáculo para a restauração das lavouras decadentes.

O presente trabalho, planejado em 1958 pelos engenheiros agrônomos Walter Lazzarini e Coaracy Moraes Franco, teve por finalidade principal pesquisar a viabilidade do cultivo do cafeeiro em solos pobres, especialmente em matéria orgânica, através do emprego de fertilizantes exclusivamente químicos.

Para esse fim foi escolhida uma área de solo que apresentava fertilidade natural excepcionalmente baixa, atestada pela vegetação nativa existente $\circ$ que foi confirmado posteriormente pelas análises químicas efetuadas.

Até então prevalecia entre os agricultores a crença de que o plantio do cafeeiro como atividade econômica apenas deveria ser tentado em solos de mata-virgem, recém-desbravados, e que apresentassem além de um elevado teor de matéria orgânica, algumas características físico-químicas e condições climáticas específicas correlacionadas com a presença de alguns padrões vegetais facilmente identificáveis pelos entendidos.

A expressões "cheiro-do-mato", "bafo-do-sertão", "pio-do-macuco" e outras muito em voga no passado entre os cafeicultores, caracterizam bem a importância que então era atribuída à presença de um alto teor de matéria orgânica no solo para o cultivo do cafeeiro. A evolução da cultura cafeeira no Brasil foi até pouco tempo uma constante procura de terras novas, à medida que os cafezais mais antigos entravam em decadência.

Não obstante, já em 1929 Theodureto de Camargo e colaboradores iniciavam um experimento de adubação de cafeeiros na região de Campinas, posteriormente analisado e publicado por Fraga e Conagin (2) e que apesar das quantidades bastante modestas aplicadas, apresentou uma reação notável para alguns tratamentos à base exclusiva de adubos químicos.

Experimentos de adubação mineral iniciados em latossolo roxo da região de Ribeirăo Preto em 1950 e em 1953, e posteriormente publicados por Lazzarini \& outros (4), e Franco \& outros (3), já evidenciavam desde as primeiras produções a viabilidade econômica do emprego exclusivo de adubos minerais para o cafeeiro.

O elhor conhecimento das exigências nutricionais do cafeeiro e o emprego de técnicas mais adequadas de fertilização em decorrência de pesquisas realizadas no Instituto Agronômico, levaram a Seção de Café desse órgăo, em 1957, a mudar a orientação que vinha adotando nas recomendações de adubação para a cultura, passando desde então a reco- 
mendar o emprego de adubações químicas mais intensivas e mais completas, subdivididas em várias aplicações durante o período chuvoso (1).

O emprego de adubação orgânica passou a ser considerado como complementar e aconselhável sempre que ocorram razões específicas que justifiquem a sua utilização, não sendo porém essencial.

No presente trabalho procurou-se determinar o efeito de adubações exclusivamente minerais em solo de muito baixa fertilidade natural e baixo teor de matéria orgânica, sobre o crescimento e a produção do cafeeiro, comparativamente ao processo clássico da aplicação do esterco de curral complementado ou não com outros fertilizantes.

\section{2 - MATERIAL E METODOS}

O experimento, conduzido no Horto Florestal do Estado, em Batatais-SP., foi instalado em latossolo vermelho-amarelo, fase arenosa, transição para barrento, apresentando vegetação natural característica de campo cerrado. A altitude local é de aproximadamente 880 metros, latitude $20^{\circ} 55^{\prime}$ $\mathrm{S}$, e longitude $47^{\circ} 40^{\prime} \mathrm{W}$.

As condições climáticas da regiāo são altamente favoráveis ao cultivo de Coffea arabica $L$.

A análise química do solo original, baseada em cinco amostras coletadas na profundidade de 0 a $10 \mathrm{~cm}$, em pontos năo adubados, apresentou os resultados do quadro 1.

QUADRO 1. - Resultados da análise quimica de cínco amastras de solo, coletadas em pontos não adubados do experimento de adubaçäo e calagem do cafeelro em campo cerrado no Horto Florestal em Batatais, SP

\begin{tabular}{|c|c|c|c|c|c|c|c|c|}
\hline AMOSTRA & $\mathrm{pH}$ & $\mathbf{A l}^{3-1}$ & $\mathbf{H}^{-}$ & $\mathbf{N}$ & $\mathbf{P O}_{4}{ }^{3-}$ & $\mathbf{K}^{-}$ & $\mathrm{Ca}^{2+}$ & $\mathbf{M g}^{2+}$ \\
\hline & & $\begin{array}{l}\mathrm{e} \cdot \mathrm{m} / \\
100 \mathrm{~g}\end{array}$ & $\begin{array}{r}\text { e.mg/ } \\
100 \mathrm{~g}\end{array}$ & $\%$ & $\begin{array}{l}\text { e.mg/ } \\
100 g\end{array}$ & $\begin{array}{c}\text { e.mg/ } \\
100 \mathrm{~g}\end{array}$ & $\begin{array}{l}\text { e.mg/ } \\
100 g\end{array}$ & $\begin{array}{l}\text { e.mg/ } \\
100 \mathrm{~g}\end{array}$ \\
\hline $1 \ldots \ldots \ldots \ldots$ & 4,45 & 0,51 & 2,70 & 0,07 & 0,02 & 0,05 & 0,40 & 0,24 \\
\hline $2 \ldots \ldots \ldots \ldots$ & 4,40 & 0,68 & 2,93 & 0,08 & 0,03 & 0,07 & 0,24 & 0,24 \\
\hline $3 \ldots \ldots \ldots \ldots$ & 4,50 & 0,51 & 2.79 & 0,08 & 0,02 & 0,07 & 0,16 & 0,08 \\
\hline $4 \ldots \ldots \ldots$ & 4,50 & 0,64 & 2,70 & 0,08 & 0,03 & 0,06 & 0,16 & 0,16 \\
\hline $5 \quad \ldots \ldots \ldots \ldots$ & 4,50 & 0,55 & 2,53 & 0,06 & 0,04 & 0,07 & 0,15 & 0,24 \\
\hline
\end{tabular}

A análise fisica revelou que a textura do solo é arenosa-barrenta, na camada de 0 a $40 \mathrm{~cm}$ de profunddade, e barrenta nas camadas inferiores.

$\mathrm{Na}$ área do experimento foi retirado um perfll de solo, para análise granulométrica e determinaçăo da dísponibilldade de água. Os resultados foram posteriormente publicados por Medina \& Grohmann (6). 
No quadro 2 săo apresentadas as características físicas gerais e a classificação granulométrica do solo.

QUADRO 2. - Características físicas gerais do solo de campo cerrado do local do experimento de adubaçäo de cafeeiro no Horto Florestal em Batatais, SP

\begin{tabular}{c|r|r|r|r|l}
\hline Profundidade & Argila & Limo & $\begin{array}{c}\text { Areia } \\
\text { fina }\end{array}$ & $\begin{array}{c}\text { Areia } \\
\text { grassa }\end{array}$ & Classificaçăo \\
\hline $\mathrm{cm}$ & $\%$ & $\%$ & $\%$ & $\%$ & \\
$0-20$ & 21,0 & 4,8 & 22,7 & 51,5 & Arenoso-bar. \\
$20-40$ & 23,0 & 2,2 & 23,3 & 51,5 & Arenoso-bar. \\
$40-60$ & 25,5 & 4,0 & 22,5 & 48,0 & Barrento \\
$60-80$ & 32,5 & 2,5 & 27,0 & 38,0 & Barrento \\
$80-120$ & 31,7 & 1,0 & 30,8 & 36,5 & Barrento \\
\hline
\end{tabular}

Cobertura vegetal natural - A vegetação que existia na área era típica de campo cerrado, com predominancia de plantas rasteiras, especialmente gramíneas e alguns arbustos esparsos com altura năo superior a trés metros.

Plano experimental - Utilizou-se delineamento estatístico em blocos ao rcaso com olto tratamentos e seis repetiçōes, compreendendo um fatorial de $2 \times 2$ para cálcio + magnésto.

\section{Tratamentos:}

1 - Controle sem adubo

2 - Esterco

3 - Esterco + NPK

4 - Esterco + NPK + calcário dolomitico

5 - NPK

6 - NPK + calcário

7 - NPK + micronutrientes

8 - NPK + micronutrientes + calcório

$\mathrm{Na}$ escolha dos tratamentos levou-se em consideraçăo a extrema deficiência do solo, incluindo-se todos os macronutrientes e alguns dos micronutrientes com malor probabilidade de constituirem problemas de carencla. A partir de 1963, tendo sido verificada a năo existência de falta de $\mathrm{Fe}, \mathrm{Mn}$ e $\mathrm{Cu}$, a aplicaçăo de micronutrientes reduziu-se a boro e zinco.

Doses e formas de aplicaģa - As doses dos fertllizantes e corretivos foram estabelecidas tendo em vista as necessidades do cafeeiro para a obtençáo de colheitas normais, levando-se em conta as suas exigênclas minerais. A técnica de aplicação dos fertilizantes foi estabelecida com base na experiéncla já adquirida nos experimentos conduzidos nas estações experimentais do Instituto Agronômico.

Esterco - O esterco fol aplicado todos os anos, inictalmente nas covas de plantio, em mistura com a terra, e nos anos subsequentes distribuidos em cobertura no solo sob a projeção da copa dos cafeeiros. No plantio a dose aplicada fol de 20 litros por cova de quatro plantas. 
A partir do $3 .^{\circ}$ ano foram efetuadas aplicaçōes anuais na base de 40 litros de esterco por cafeeiro, para o tratamento 2. Para os tratamentos 3 e 4 foram aplicadas metade das quantidades de esterco e de NPK.

Os tratamentos 5, 6, 7 e 8 foram adubados desde 0 início exclusivamente com fertillzantes minerais, não tendo sido empregado o esterco em nenhuma ocasiąo, nem mesmo no plantio.

As quantidades anuais por planta, de fertilizantes químicos aplicados forar: as seguintes:

Nitrogênio - No $1 .^{\circ}$ ano $20 \mathrm{~g}$ de $\mathrm{N}$ por cafeeiro, na forma de sulfato de amónio, subdiviđidas em três aplicaçóes.

No $2 .^{\circ}$ e $3 .^{\circ}$ ano foram aplicados respectivamente 40 e $80 \mathrm{~g}$ de $\mathrm{N}$ por planta. A partir do $4 .^{\circ}$ ano a dose de $\mathbf{N}$ manteve-se em $120 \mathrm{~g}$ de $\mathrm{N}$, subdivididos em quatro fracionamentos, na forma de sulfato de amônlo até 1964; a partir de então foram aplicadas alternadamente duas fontes de $\mathbf{N}$, sulfato de amónio e Nitrocálcio, totalizando cada uma $\mathbf{5 0 \%}$ da dose anual do elemento.

Fósforo - No plantio foram aplicados $200 \mathrm{~g}$ de superfosfato simples $+200 \mathrm{~g}$ de fosfato-de-olinda, em mistura com a terra das covas. Nos anos subsequientes foram apltcados $200 \mathrm{~g}$ de fosfato-de-olinda por planta e por ano, até 1964. A partir de 1965 o fosfato-de-olinda foi substituído pelo superfosfato simples, na dose de $200 \mathrm{~g}$ por planta e por ano. A partir do $2 .^{\circ}$ ano os adubos fosfatados foram sempre aplicados a lanço, sob a projeção da copa dos cafeeiros.

Potássio - No plantio, $25 \mathrm{~g}$ de $\mathrm{KCl}$ por cova. No $2 .^{\circ}$ e $3 .^{\circ}$ ano ,respectivamente 50 e $100 \mathrm{~g}$ de $\mathrm{KCl}$ por cafeeiro, e a partir do $4 .^{\circ}$ ano, $200 \mathrm{~g}$ de $\mathrm{KCl}$ por cafeeiro e por ano.

A aplicaçáo do $\mathbf{N}$ e do $\mathbf{K}$ fol leita sempre em cobertura no solo e em toda a volta dos cafeeiros, no limite de projeçăo da copa, subdividindo-se a dose anual em quatro fracionamentos, dentro do periodo de outubro a abril.

Micronutrientes - Até 1962 foram aplicadas duas pulverizaçōes anuais da seguinte solução:

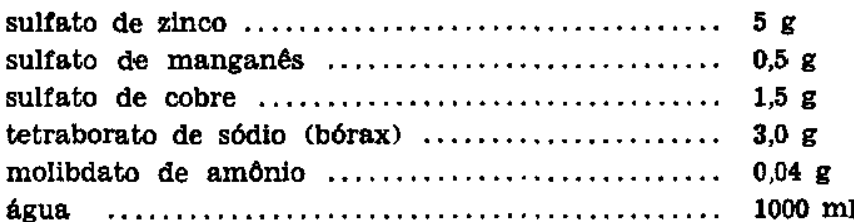

No $1 .^{\circ}$ ano de campo foram apllcados $100 \mathrm{ml}$ de soluçáo por planta. No $2 .^{\circ}$ e $3 .^{\circ}$ ano aplicaram-se respectivamente 200 e $300 \mathrm{ml}$ por cafeeiro, volume esse elevado para $1000 \mathrm{ml}$ no 4. ano.

A partir do ano agrícola 1963/64, tendo-se verificado ser insuficiente reaçåo do zinco e do boro aplicados por va follar, esses micronutrientes passaram a ser empregados diretamente no solo, nas doses de $20 \mathrm{~g}$ de sulfato de zinco e $20 \mathrm{~g}$ de bórax por planta e por ano, segundo resultados obtidos em ensaio de modo de aplicação de sulfato de zinco em terra sob cerrado, conduzido pela seçăo de Café em Campinas (7). Suprimiu-se também a aplicaçấo dos demals micronutrientes.

Calcário - Antes do plantio fol efetuada uma aplicaçáo de $50 \mathrm{~g}$ de calcário dolomitico por cova, nos tratamentos correspondentes. Essa quantidade fol misturada com a terra utilizada no enchimento das covas. No $2 .^{\circ}, 3 .^{\circ}$ e $4 .^{\circ}$ ano, foram aplicados respectivamente 100,200 e $400 \mathrm{~g}$ de calcário por cafeeiro. 
Nos anos de 1963, 1966 e 1968, foram efetuadas mals três aplicaçōes de calcário na base de 1 quilo por cafeeiro cada uma.

Os cafeeiros utllizados no experimento pertenciam ao cultivar mundo novo, linhagem CP 379-19, tendo sido plantadas quatro mudas por cova, dispostas em quadro e distançiadas entre si de $20 \mathrm{~cm}$.

O espaçamento utilizado foi de $3 \times 2 \mathrm{~m}$, compreendendo cada parcela 16 cafeeiros distribuídos em quatro linhas de quatro plantas cada uma.

A área total do ensaio corresponde a $4608 \mathrm{~m}^{2}$.

A instalaçāo do experimento deu-se em março de 1958, quando fol efetuado - plantio das mudas.

A colhelta foi efetuada sempre de uma só vez por ano e somente as produçōes das quatro plantas internas de cada parcela foram utilizadas na determinação do rendimento e no cálculo estatístico.

\section{3 - RESULTADOS E DISCUSSÃO}

As produções de café, por tratamento, estão agrupadas por biênios no quadro 3.

QUADRO 3. - Produçס́es de café beneficiado, em $\mathrm{kg} / \mathrm{ha}$, obtidas no periodo de 1960 a 1969, no ensaio de adubaçăo instalado em solo de campo cerrado, no Horto Florestal do Estado, em Batatais, SP

\begin{tabular}{|c|c|c|c|c|c|c|c|}
\hline \multirow{2}{*}{\multicolumn{2}{|c|}{$\begin{array}{l}\text { Trata- } \\
\text { mento } \\
(* *)\end{array}$}} & \multicolumn{5}{|c|}{ PRODUÇAO DE CAFE POR BIENIOS (*) } & \multirow{2}{*}{$\begin{array}{l}\text { Média } \\
\text { anual } \\
1960-1969\end{array}$} \\
\hline & & $60 / 61$ & $62 / 63$ & $64 / 65$ & $66 / 67$ & $68 / 69$ & \\
\hline 5 & $\ldots \ldots \ldots$ & $194 \mathrm{~d}$ & $121 \mathrm{~d}$ & $490 \mathrm{c}$ & $785 \mathrm{~d}$ & 372 a & $196 \mathrm{~cd}$ \\
\hline 7 & $\ldots \ldots \ldots$ & $382 \mathrm{~cd}$ & $128 \mathrm{~cd}$ & 385 bc & 1458 bed & $701 \mathrm{a}$ & $305 \mathrm{~cd}$ \\
\hline 2 & $\ldots \ldots \ldots$ & $264 \mathrm{~cd}$ & 424 bed & $813 \mathrm{bc}$ & 1628 ab & 351 a & 498 bed \\
\hline 6 & $\ldots \ldots \ldots$ & 535 bed & 722 bed & $1431 \mathrm{abc}$ & $1000 \mathrm{~cd}$ & 531 a & 517 abc \\
\hline 3 & $\ldots \ldots \ldots$ & 740 abc & $1142 a b$ & $1733 \mathrm{ab}$ & 2552 a & $441 \mathrm{a}$ & $561 \mathrm{ab}$ \\
\hline 8 & $\ldots \ldots$ & 1014 a & 899 bc & 2368 a & 2479 a & $778 \mathrm{a}$ & 754 a \\
\hline 4 & $\ldots \ldots \ldots$ & $938 \mathrm{ab}$ & 1677 a & 2271 a & 2316 a & $413 a$ & 762 \& \\
\hline & m.s. & 428 & 776 & 1385 & 971 & 530 & 286 \\
\hline
\end{tabular}

(*) Letras comuns expressam diferenças não significativas, na comparação das medias.

(**) O tratamento 1 - não adubado, năo chegou a produzir, tendo morrido quase todos os cafeeiros durante os trés primeiros anos do experimento. 


\section{1 - EFEITO DOS TRATAMENTOS SOBRE O CRESCIMENTO VEGETATIVO DOS CAFEEIROS}

As plantas testemunhas (tratamento 1) desenvolveram-se muito pouco durante os primeiros anos após o plantio, não chegando a ultrapassar os $80 \mathrm{~cm}$ de altura. Praticamente todas as plantas desse tratamento já estavam mortas 4 anos após iniciado o ensaio. Em 1961 os cafeeiros remanescentes apresentavam quantidade reduzida de folhas, quase sempre com sintomas característicos de falta de enxofre (5). A análise foliar dessas plantas, realizada pela Seção de Química Analítica do Instituto Agronômico, revelou teores de S (em enxofre-sulfato) em torno de 50ppm, valor muito inferior ao nível considerado como normal para esse nutriente (200 a $400 \mathrm{ppm}$ de enxofre-sulfato).

As plantas do tratamento 2 apresentaram desenvolvimento regular, tendo atingido altura aproximada de 2 metros. As folhas apresentavam, com frequiência, sintomas de deficiência de nitrogênio e, em menor proporção, da carência de magnésio.

Sintomas da deficiência de zinco e de boro foram também observados, porém em menor escala.

Nas parcelas do tratamento 3 os cafeeiros em geral apresentavam porte $\mathrm{e}$ aspecto sensivelmente melhores que no tratamento 2 . Os sintomas de falta de nitrogênio eram praticamente inexistentes, com exceção das plantas que apresentavam elevada produção pendente, na época da inspeção.

Sintomas de deficiência de magnésio, zinco e boro foram observados neste tratamento com grande intensidade e de forma generalizada.

As plantas dos tratamentos 4 e 8 apresentaram excelente desenvolvimento vegetativo, atingindo altura média em torno de $2,5 \mathrm{~m}$.

As folhas dos cafeeiros nesses dois tratamentos apresentavam quase sempre coloração e desenvolvimento normais, com ocorrência mínima de sintomas específicos de deficiências minerais.

Os cafeeiros do tratamento 5 apresentaram crescimento bastante inferior aos demais, não ultrapassando a altura de $1,5 \mathrm{~m}$. Observou-se alta incidência de sintomas de deficiência de magnésio, zinco e boro, conferindo às plantas um aspecto inteiramente anormal. Nas parcelas do tratamento 6 os cafeeiros apresentavam desenvolvimento um pouco melhor que aquelas do tratamento 5 , não ocorrendo praticamente os sintomas de carência de $\mathrm{Mg}$, porém persistindo os sintomas de deficiência de zinco e boro. Os cafeeiros do tratamento 7 apresentaram desenvolvimento em altura semelhante àqueles do tratamento 5 , com correção praticamente total da carência de zinco e de boro.

Nos anos de 1967 e 1968 o experimento foi prejudicado respectivamente por geada e granizo, fenômenos esses que afetaram negativamente 
a produção do biênio $68 / 69$, a qual foi sensivelmente inferior à dos dois biênios precedentes.

Levando em conta que as produções obtidas nos dois primeiros biênios $(60 / 61$ e 62/63) foram limitadas pela dose insuficiente de micronutrientes até então aplicada e que no último biênio os cafeeiros foram afetados por fenômenos climáticos, apenas os biênios 64/65 e 66/67 apresentam níveis de produção adequados para servirem de base para o estudo da viabilidade econômica do cultivo do cafeeiro em solos dessa natureza.

A maior produção do experimento foi obtida em 1965, após uma colheita nula no ano anterior, em consequiência da forte seca ocorrida em 1963.

Naquele ano as maiores produções corresponderam aos tratamentos 8-(NPK + B + Zn + Calcário) e 4-(Esterco+NPK +Calcário).

As produçōes do experimento em 1965, convertidas em quilogramas de café beneficiado por hectare foram as seguintes:

\begin{tabular}{|c|c|}
\hline Tratamento & $\begin{array}{l}\text { Produção } \\
\text { (kg/ha) }\end{array}$ \\
\hline 3 - ENPK & 1734 \\
\hline 6 - NPK+calcário & 1433 \\
\hline $2-\mathrm{E} \ldots \ldots \ldots \ldots \ldots$ & 800 \\
\hline $4-\mathrm{E}+\mathrm{NPK}+$ calcário $\ldots$ & 2061 \\
\hline $5-\mathrm{NPK} \ldots \ldots \ldots$ & 491 \\
\hline $7-\mathrm{NPK}+\mathrm{Zn}+\mathrm{B}$ & 401 \\
\hline $8-\mathrm{NPK}+\mathrm{Zn}+\mathrm{B}+$ calcário & 2271 \\
\hline
\end{tabular}

\section{2 - ANALISE DE VARIANCIA}

A análise de variância foi feita por biênios (totalizando cinco biênios) e para o total do período de dez anos.

$O$ efeito para tratamentos foi desdobrado nos contrastes seguintes: contraste $A$, efeito do esterco (tratamentos 2,3 e 4 versus tratamentos $5,6,7$ e 8); contraste $\mathbf{B}$, efeito da adição do calcário ao esterco (tratamento 3 versus tratamento 4); contraste C, efeito da adição do NPK e calcário ao esterco (tratamento 4 versus tratamentos 3 e 2); contraste $D$, efeito do calcário como corretivo da deficiência de $\mathrm{Mg}$ (tratamentos 6 e 8 versus tratamentos 5 e 7); contraste $\mathbf{E}$, efeito dos micronutrientes (tratamentos 7 e 8 versus tratamentos 5 e 6 ); contraste $\mathbf{F}$, efeito da interação 
do calcário aplicado em presença dos micronutrientes (tratamentos 8 e 5 versus tratamentos 6 e 7).

Para o decênio foram calculados também os efeitos das interações dos contrastes citados, com os biênios.

Os resultados das análises da variância apresentados por biênios e para o decênio são expressos em quilogramas de café beneficiado.

Biênio 1960-1961: ao nível de $1 \%$ de probabilidade foram significativos os contrastes B, C, D, e E;

Biênio 1962-1963: ao nível de $1 \%$ de probabilidade foram significativos os contrastes A, B, C e D;

Biênio 1964-1965: ao nível de $1 \%$ de probabilidade foi significativo o contraste $\mathrm{D}$, e ao nível de $5 \%$ de probabilidade, os contrastes B é C;

Biênio 1966-1967: ao nível de $1 \%$ de probabilidade foram significativos os contrastes A, B, D e F;

Biênio 1968-1969: ao nivel de $5 \%$ de probabilidade foram significativos os contrastes B e E; os contrastes A, B, C e F foram negativos;

Decênio 1960-1969: os quadrados médios dos contrastes foram comparados com o quadrado médio da interação: tratamento versus biênio, com 24 graus de liberdade.

Os contrastes A, B, C e E mostraram-se significativos ao nível de $5 \%$ de probabilidade. $O$ contraste $D$ mostrou-se significativo ao nível de $1 \%$ de probabilidade.

As interações contrastes versus biênios foram testadas com o erro b, com 140 graus de liberdade e todas mostraram-se significativas ao nível de $1 \%$ de probabilidade, com exceção da interação biênio versus contraste $\mathrm{E}$, que não se mostrou significativa.

Para comparação entre as médias foi usado o teste de Tukey ao nível de 5\% de probabilidade, cujos resultados se encontram no quadro 3. Nesse quadro os tratamentos foram dispostos por ordem crescente das médias de produção e observa-se que em todos os períodos estão os tratamentos $5,7,2$ e 6 num grupo de menores médias, e os tratamentos 3,8 e 4 num grupo de maiores médias. Ambos os grupos não apresentam diferenças estatísticas entre as médias dos tratamentos componentes de cada grupo, segundo o teste de Tukey ao nível de $5 \%$ de probabilidade.

Comparando duas a duas as produçōes dos períodos correspondentes aos tratamentos 5 e 7 , e 6 e 8 , apresentadas no quadro 3, observa-se que o efeito da aplicação dos micronutrientes é aditivo, visto que os aumentos produzidos pelas aplicações dos mesmos na presença de apenas NPK é menor que os aumentos verificados pelas aplicações na presença de NPK e calcário. 
Por outro lado, comparando duas a duas as produções dos períodos correspondentes aos tratamentos 3 e 4, 5 e 6 e 7 e 8 , verificamos os grandes aumentos de produções obtidos pela adição do calcário às adubações minerais ou sobre o esterco. A adição de NPK ao esterco é benéfica para a produção, como já se conhecia e pode ser verificado comparando-se os tratamentos 2,3 e 4 , e também de acordo com teste $F$ para os contrastes B e C.

\section{3 - VIABILIDADE DO PLANTIO DE CAFE EM SOLOS DE CERRADO}

Tomando por base as produções médias obtidas nos biênios 1964-1965 e 1966-1967 para os tratamentos 3, 4 e 8, respectivamente de 2143, 2294 e $2424 \mathrm{~kg} /$ ha de café em coco em 1660 covas plantadas a $3 \mathrm{~m}$ x $2 \mathrm{~m}$, verifica-se que estão muito acima da produção média do Estado de São Paulo, que é da ordem de 1500 quilogramas de café em coco por hectare. Tais produções indicam a viabilidade da cafeicultura em solos com vegetação de cerrado, desde que as condições climáticas e físicas do solo sejam favoráveis, como foi o caso do solo utilizado no presente experimento.

\section{4 - CONCLUSŐES}

A análise dos dados e as observaçōes efetuadas durante o transcorrer do experimento permitem as seguintes conclusões:

a) A adubação química exclusiva com NPKS complementada com calagem e micronutrientes, apresentou o mesmo nível de produção do tratamento com esterco mais adubação química com NPKS mais calcário, destacando-se dos demais tratamentos e demonstrando não ser essencial, no caso, o emprego do adubo orgânico.

b) O emprego do calcário dolomítico foi altamente eficaz na correção da carência de magnésio e também no aumento da produção.

c) As aplicaçóes de bórax (tetraborato de sódio) e de sulfato de zinco no solo foram altamente eficientes na correção dos sintomas de deficiência de $\mathbf{B}$ e $\mathrm{Zn}$, sendo também elevados seus efeitos no aumento da produção, quando empregados na presença de calcário.

d) O calcário e os micronutrientes apenas apresentaram efeitos adil.vos, não tendo havido interação entre os mesmos.

e) O efeito da adição de NPKS ao esterco foi significativo no aumentio de produçâo.

f) Os dados do presente trabalho comprovam a viabilidade da exploração econômica da cultura cafeeira no latossolo vermelho-amarelo estudado, com emprego de adubaçōes exclusivamente químicas. 
FERTILIZING FOR COFFEE PLANT ON A RED YELLOW LATOSOL

\section{SUMMARY}

This paper presents the results of an experiment of coffee fertilization on a Red Yellow Latosol of extremely low fertility. This soil was formerly considered improper for economical agriculture.

Three treatments based on the application of barnyard manure and four treatments employing only mineral fertilizers were used.

The effects of the treatments were studied for the period 1960 to 1969. The yields showed that the use of mineral fertilizers plus lime and micronutrients and this same mineral misture plus a dose of barnyard manure gave the best responses.

The application of borax and zinc sulphate as soil dressings corrected efficiently the deficiencies of boron and zinc and increased the production when applied together with dolomite.

The application of dolomite was highly efficient for correction of magnesium deficiency and increased significantly the yields.

The results showed that it is possible to cultivate coffee successfully on a Red Yellow Latosol of extremely low fertility using exclusively mineral fertilizers.

\section{LITERATURA CITADA}

1. INSTITUTO AGRONOMICO, Campinas. Comunicado sobre novos conceitos da fertilização do cafeeiro, emitido a 15 de abril de 1958. In: Relatório "Experimentação cafeeira 1929-1963" - Campinas 1967. p. 134-135.

2. FraGA, C. G. \& CONAGIN, A. Delineamentos e análise de experimentos com cafeeiro. Bragantia 15:177-191, 1956.

3. FRANCO, C. M.; LAZZARINI, W.; CONAGIN, A.; REIS, A. J. \& MORAES, F.R.P. Manutenção de cafezal com adubaçäo exclusivamente mineral. Bragantia $19: 523-546,1960$.

4. LAZZARINI, W.; MORAES, F.R.P.; TOLEDO, S. V. \& FIGUEIREDO, J. I. Ensaio de adubação mineral e orgânica. In "Experimentaçăo Cafeeira 1929-1963". Campinas, Instituto Agronômico, 1967. p. 157-160.

5. LOTT, W. L.; MCLUNG \& MEDCALF, J. C. Deficiência de enxofre no cafeeiro. Săo Paulo, IBEC Research Inst. (Bol 22)

6. MEDINA, H. PENNA \& GROHMANN. F. Disponibilidade de água em alguns solos sob cerrado. Bragantia 25:65-75, 1966.

7. TOLEDO, s. V. Modo de aplicaçăo de zinco em cafeeiro. In: XVII Reuniáo anual da S.B.P.C., Belo Horizonte, MG, 1965. 